\title{
An Exploratory Study of Spiritual Care at the End of Life
}

Timotby P. Daaleman, DO, MPH

Barbara M. Usher, RN, PbD,

APRN-BC, BC-PCM ${ }^{2}$

Sharon W. Williams, $P b D^{3}$

Jim Rawlings, MDiv, DMin ${ }^{4}$

Laura C. Hanson, MD, MPH

'Department of Family Medicine, Cecil G. Sheps Center for Health Services Research, University of North Carolina at Chapel Hill, Chapel Hill

${ }^{2}$ Department of Palliative Care and Medical Ethics, University of Pittsburgh Medical Center, Pittsburgh, Pennsylvania

${ }^{3}$ Department of Allied Health Services, University of North Carolina at Chapel Hill, Chapel Hill

${ }^{4}$ Department of Pastoral Care, University of North Carolina Hospital, University of North Carolina at Chapel Hill, Chapel Hill

${ }^{5}$ Division of Geriatric Medicine, UNC Palliative Care Program, Cecil G. Sheps Center for Health Services Research, University of North Carolina at Chapel Hill, Chapel Hill

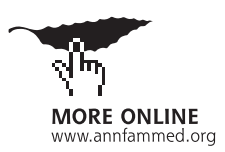

Conflicts of interest: the authors report no conflicts of interest

\section{CORRESPONDING AUTHOR}

Timothy P. Daaleman, DO, MPH Department of Family Medicine Cecil G. Sheps Center for Health Services Research Campus Box 7595

University of North Carolina at Chapel Hill Chapel Hill, NC 27599-7595 tim_daaleman@med.unc.edu

\begin{abstract}
PURPOSE Although spiritual care is a core element of palliative care, it remains unclear how this care is perceived and delivered at the end of life. We explored how clinicians and other health care workers understand and view spiritual care provided to dying patients and their family members.
\end{abstract}

METHODS Our study was based on qualitative research using key informant interviews and editing analysis with 12 clinicians and other health care workers nominated as spiritual caregivers by dying patients and their family members.

RESULTS Being present was a predominant theme, marked by physical proximity and intentionality, or the deliberate ideation and purposeful action of providing care that went beyond medical treatment. Opening eyes was the process by which caregivers became aware of their patient's life course and the individualized experience of their patient's current illness. Participants also described another course of action, which we termed cocreating, that was a mutual and fluid activity between patients, family members, and caregivers. Cocreating began with an affirmation of the patient's life experience and led to the generation of a wholistic care plan that focused on maintaining the patient's humanity and dignity. Time was both a facilitator and inhibitor of effective spiritual care.

CONCLUSIONS Clinicians and other health care workers consider spiritual care at the end of life as a series of highly fluid interpersonal processes in the context of mutually recognized human values and experiences, rather than a set of prescribed and proscribed roles.

Ann Fam Med 2008;6:406-411. DOI: 10.1370/afm.883.

\section{INTRODUCTION}

lthough the healing professions have roots in religious and spiritual
traditions, ${ }^{1}$ end-of-life care is often provided in a technological and
spiritually barren landscape. ${ }^{2}$ In the United States, for example, $67 \%$ of people die in hospitals or long-term care facilities without assured access to spiritual care. ${ }^{3}$ Patients approaching the end of life traverse an unknown spiritual terrain, and a growing body of research shows that this journey often awakens a uniquely spiritual dimension among patients and family caregivers; most desire acknowledgment and support for their spiritual needs from health care workers ${ }^{4-7}$ Physicians, ${ }^{8}$ nurses,${ }^{9}$ and others are being called upon to assume greater responsibility for providing spiritual care, tasks that have been traditionally assigned to pastoral caregivers and clergy..$^{10}$ Controversy remains, however, over whether clinicians and other health care workers can or should provide this care..$^{11-13}$

The definition of spiritual care is uncertain and has multiple interpretations. A theological or religious understanding highlights the facilitation of individual meaning, connectedness, and inner peace and is often inclusive of religious rituals, beliefs, and communities. ${ }^{14}$ Nursing studies define spiritual care as referring to others, facilitating religious rituals and practices, and being present to patients. ${ }^{15}$ Despite its promotion by the Institute of Medicine ${ }^{16}$ the National Hospice and Palliative Care Organization, ${ }^{17}$ and 
the World Health Organization, ${ }^{18}$ spiritual care at the end of life remains poorly understood, and it is unclear how this type of care is actually delivered. ${ }^{19,20}$ Our study was part of a multimethod project to examine the spiritual care of dying patients and family caregivers. ${ }^{21}$ To gain insight about this type of care, we used qualitative research methods to explore the perspectives of clinicians and other health care workers who were identified by dying patients and family members as providing spiritual care at the end of life.

\section{METHODS}

The qualitative study design used semistructured interviews that were conducted by a study investigator (B.M.U.). We used a nominated 2-stage sampling procedure. First, patients were recruited during a 13 month period from January 2005 to February 2006 from palliative care, family medicine, and geriatric medicine inpatient services, as well as from oncology clinics, within a university tertiary care health system in the southeastern United States for participation in a survey study of spiritual care. ${ }^{21}$ Patients were eligible if they were capable of understanding and responding to interview questions, and their attending physicians' clinical judgement was that they would not be surprised if the patient died within the year. These patients' family caregivers were also eligible for interview regardless of the patient's capacity; they were interviewed as potential recipients of spiritual care, not as surrogates for patients' experiences.

Both patients and family caregivers were asked to identify specific individuals who were most involved in the patients' spiritual care, and more than one person could be named. A total of 38 patients and 65 family caregivers identified 237 spiritual caregivers; 95 (41\%) were family or friends, 38 (17\%) were clergy, and 66 (29\%) were clinicians and other health care workers. Because our focus was on the perspectives of clinicians and other health care workers, we used these nominees to select participants from several health care disciplines (eg, medicine, nursing) to enhance variation in our sample. ${ }^{22}$ As a palliative care coordinator in the health care system, the interviewing investigator had professional interactions with several of the participants.

Our review of the literature on spiritual care and the clinical experience of the investigators contributed to development of a semistructured interview guide (Supplemental Appendix, available online at http://

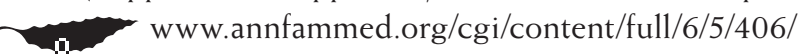

m DC1) that explored participants' perceptions of endof-life care encounters. Participants were asked to describe 2 patient interactions: 1 in which spiritual care was a core element and the caregiver was confident in delivering this care, and 1 in which the caregiver had difficulty providing spiritual care. The guide included prompts about approaches and strategies regarding ethnic, racial, and religious differences, as well as factors that facilitated or impeded the provision of spiritual care. We tested the interview guide with 2 participants, which resulted in minor changes in formatting. In addition, new themes that emerged from the interviews were incorporated and tested in subsequent interviews.

The interviews were conducted in person, tape recorded, professionally transcribed, and checked for accuracy by a single investigator who is a nurse experienced in both palliative care and qualitative research methods. Transcripts were iteratively reviewed during data collection by the interviewer and the principal investigators - a family physician with experience in qualitative research (T.P.D.) and a geriatrician with expertise in palliative care (L.C.H.). Initial coding was performed by the interviewer and the family physician. The interviews were read to identify emerging patterns using editing analysis, in which meaningful segments of text were coded. ${ }^{22}$ Concurrent independent analyses were performed by a chaplain who directs a clinical pastoral education program at an academic medical center (J.R.) and a gerontologist with expertise in caregiving and older minority adults (S.W.W.). All investigators subsequently met and iteratively reviewed the codes to reach consensus; themes were compared within and across interviews.

The final categories were reviewed by 3 participants in a process known as member checking. ${ }^{22}$ No new themes emerged in the last few interviews, after which we achieved data saturation. The data were analyzed using qualitative research software (QSR, N6), ${ }^{23}$ and the study was approved by the University of North Carolina at Chapel Hill Institutional Review Board before its initiation.

\section{RESULTS}

All 12 participants were identified as spiritual caregivers by dying patients or their family members. The average age was 44 years (range 27 to 60 years); one-half were women. Nine were white, and 1 each was African American, Asian American, and Hispanic/ Latino. The professional backgrounds of the participants were as follows: 8 were physicians, 2 were chaplains/pastoral caregivers, 1 was a nurse, and 1 worked in facilities services/housekeeping. Most participants considered themselves to be not religious or slightly religious $(n=7)$ and not or slightly spiritual $(n=9)$. There was heterogeneity in self-reported faith traditions: nondenominational $(\mathrm{n}=1)$, Hindu $(\mathrm{n}=1)$, American Methodist Episcopal Zion $(\mathrm{n}=1)$, atheist $(\mathrm{n}=1)$, 
Catholic $(\mathrm{n}=2)$, Jewish $(\mathrm{n}=2)$, and Christian $(\mathrm{n}=3)$.

Our analysis of the interviews resulted in identifying 3 major themes that were reported as core elements of spiritual care, in addition to impediments to delivering spiritual care. These themes were validated after the interviews by 3 participants, and the data suggested that interrelationships existed among the categories of spiritual caregiving. As a result, we built a conceptual framework that depicts the relationships among the categories (Figure 1). ${ }^{24}$ The principal investigator (T.P.D.) constructed an initial framework that was iteratively reviewed by the other analysts who participated in coding the data (B.M.U., J.R., S.W.W.) and then by an independent analyst with expertise in palliative care and health services research (L.C.H.).

\section{Being Present}

Being present was a dominant theme among participants, defined as a shared encounter or encounters marked by intentionality or the deliberate ideation and purposeful action of care that went beyond medical treatment, giving attention to emotional, social, and spiritual needs

What I've realized and why I did this is because it's easy to give people medicines, but it's hard to be with people when things are going tough, and I think that's the important thing (Interview 3).

I would say spiritual care is sort of care of the whole person, you know, or just being aware that it's more than just the physical body and the pain (Interview 4).

Physical proximity to the patient was a key element that facilitated communication on the caregiver's part so the caregiver could be fully attentive to the patient, sometimes transcending explicit modes of communication.

\section{Figure 1. Conceptual framework of spiritual caregiving at the end of life.}

Impediments to Spiritual Care

Lack of time

Social, religious, and cultural discordance between caregiver and patient

Lack of privacy during visit

Limited/no continuity between caregiver and patient

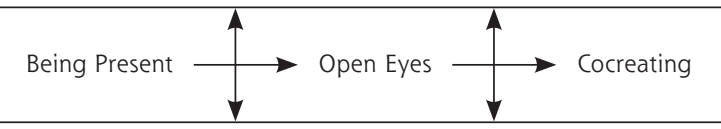

Facilitators of Spiritual Care

Ample time

Effective Communication

Caregiver's family experience with serious illness or death
I just felt like we have really kind of touched base like where everyone was coming from, and so I know what they meant and they were very openly explaining it, and I felt comfortable asking questions, just so I knew (Interview 4).

You're being introduced to a very intimate, you know, part of their lives... I think that introduces you quite early into a very intimate relationship (Interview 10).

\section{Opening Eyes}

Opening eyes was the process by which caregivers recognized and became aware of the patients' storied humanity and the individualized experience of their illness by understanding the patient's perspective of his or her illness and incorporating viewpoints from family and close friends. Although the patient's perspective was central, opening eyes was a bidirectional process, whereby patient and caregiver recognized the uniquely human dimension in the other.

I always think of spiritual care as trying to open my eyes to what the patient sees about what's happening to them, as well as opening the patient's eyes to see that I care about what...is going on with them (Interview 3).

I try to figure out what their understanding is of their disease, good prognosis or bad. I try to understand what their expectations are. I try to understand what their social situation is, and then I try to make sure I understand what family is involved or not (Interview 12).

Often participants stated that opening eyes allowed them to identify potential inner resources, such as belief systems, and outer resources, such as community and social supports, for patients.

...even though I don't believe in God myself,... I'm trying to use the patients' belief system to support what they're going through or help them (Interview 10).

I do a lot of encouraging to folks to connect with people who can support them through this time... a community that can support them at this time, to rely on the relationships in their lives that help them through hard and difficult times (Interview 8).

Opening eyes also allowed the caregiver to affirm the patients' unique experience of their illness and their life story.

...listening to stories, reaffirming what they believe, and the assurance that what they believe was real and hopeful and accessible to them (Interview 1).

\section{Cocreating}

Cocreating is a term we used to describe a mutual activity among patients, family members, and caregivers that generated a wholistic care plan focusing on maintaining the patient's humanity and dignity in the face of death. 
Our job is really kind of an outline: This is exactly where you are. This is what's happening. These are the potential problems down the road and this is what we will do (Interview 7).

I said, "Well, you know, I think I have a suggestion about what we do then with your care. That is that we take out this IV and this PICC line and get you hospice, and you go back and just gradually pull...gently, get sleepier and sleepier, and not want to eat or drink much, and you'll just drift away. Is that okay?" And she said, "Yeah" (Interview 5).

Participants reported that care planning was generated and fashioned through a process of discernment.

Spiritual care is discerning, my discerning, sometimes helping a patient discern their connection with spirit and what form that takes and how I may help them strengthen that connection - whatever or however it comes out-and be kind of a partner with them as they explore deepening that connection (Interview 5).

\section{Barriers to Spiritual Care}

The lack of sufficient time was the major barrier to spiritual care voiced by most participants.

These were really tough issues that take a lot of time and, in my mind, that they would take some time to sort these things out, and I don't think that there is sufficient time in clinic to really have these types of discussions with people, and so I think time was a barrier (Interview 9).

Social, religious, or cultural discordance between caregiver and patients sometimes created an atmosphere of mistrust and was another obstacle to care.

They [patient and family members] are like born-again Christians, and this plays a huge role in the situation, because he was diagnosed with this cancer which is incurable, and life expectancy is usually less than a year with metastatic esophageal cancer. So, from the very get-go, they only wanted me to be their physician if I believed in miracles (Interview 9).

So they really didn't have a sense of anyone that we brought to the table [from the medical team] was an ally. It was more that everybody was trying to change their belief about what was going to happen, or about how things ought to be done (Interview 2).

Finally, institutional obstacles, such as the absence of privacy and lack of continuity, were also highlighted.

You know, you're about to ask them about whether they want to be resuscitated, and the dietary people come in and take the tray. There's no way to achieve much privacy in the hospital (Interview 6).

\section{Facilitators of Spiritual Care}

Having ample time, unencumbered by competing clinical demands, to foster relationships was noted as a facilitator by many participants.
I think with that family, with lots of families, I'm somebody that people see over and over again. I'm a familiar face, hopefully welcome (Interview 1).

... and even with families I'm initially meeting, relationships don't have to be built over days and days and days. Relationships can be built over minutes and hours, especially in crises when facing end of life (Interview 8).

The second factor, which was time-dependent, was effective communication in which caregivers were able to gather information and craft a coherent clinical narrative for patients and family members.

You know the tension is not based on race or even probably differences of beliefs. The tension, in my experience, has to come from difficulty in communication or miscommunication. Admittedly, you know, I'm not really on the front line. I'm not in the emergency room, and I'm not the first person they see when they come on the floor. So I have a considerable amount of information usually by the time I go to see the patient, and I am able to summarize things and present things in a little more definitive pattern than the first people who see the patient (Interview 12).

Finally, participants reflected on their own personal experiences with serious illness and death as a facilitator of their spiritual caregiving.

My other grandmother had end-stage Alzheimer's, and so we didn't put in a feeding tube and we didn't do that, so I suppose sometimes I reference things like that.... So I do think that I came from a family that is a little bit more comfortable with doing things like that versus some families that try everything (Interview 4).

I grew up with a lot of elderly great aunts and uncles who didn't have children and, consequently, I had to provide a lot of social support for them. So I kind of, you can see this coming (Interview 11).

\section{DISCUSSION}

Despite the lack of consensus as to how spirituality is understood and defined in health care settings, there is a growing body of literature promoting spiritual care. ${ }^{20,25}$ In our conceptual framework, being present is congruent with the perspective of Puchalski and colleagues, ${ }^{26}$ who describe compassionate presence as a quality of spiritual care. Presence, according to this latter viewpoint, incorporates an intention to openness, to connection with others, and to comfort with uncertainty. ${ }^{26}$ Being present and sharing personal beliefs and experiences, or "sharing the self," were also major themes of spiritual care in a survey study of oncology nurses. ${ }^{27}$ Another qualitative study of spiritual care stakeholders noted that "being there," or empathizing, valuing, and listening and loving, were related process themes. ${ }^{28}$ 
When being effectively present to dying patients and family members, spiritual caregivers-according to the framework - are predisposed to having open eyes, promoting an awareness of the patient's illness experience. Rumbold also emphasizes the importance of mutuality in spiritual caregiving ${ }^{29}$ whereas Lunn defines spiritual care as "making a connection between yourself and that person," in which people are connected or reconnected to their core beliefs, practices, and principles. ${ }^{30}$ Our description of open eyes shares characteristics with these orientations and with a qualitative study of nursing home care staff that described intimate knowing_-or knowing what is important to residents and what they value-as a major component of spiritual care. ${ }^{31}$

Caregivers who are fully present in encounters where the patient and caregiver mutually recognize each others' humanity can engage in cocreating. The etymology of cocreating may be found in the theology of work literature, specifically in Catholic social teaching. ${ }^{32-34}$ The locus of cocreating is proximal in our framework, focusing on working out a care plan among patients, family members, and health caregivers. Puchalski describes extrinsic elements of spiritual care as appraising and communicating the patient's spiritual issues and incorporating the patient's spirituality into the care plan. ${ }^{26}$ Cocreating, from our viewpoint, shares some characteristics with these described elements, but it is more comprehensive and integrative.

Time was both a facilitator and inhibitor of spiritual care from the caregiver's perspective. A qualitative study of physicians also identified lack of time as a barrier to the psychosocial spiritual care of dying patients. ${ }^{35}$ Physicians in this earlier study described an inability to manage dynamic patient-physician relationships that were complicated by many subjective issues. ${ }^{35}$ Our data suggest that effective communication may be tied to how well caregivers gather and interpret information, and how this information is narratively presented to patients and family members.

One noteworthy finding was the marked absence of explicitly religious practices or beliefs in our data. Although this absence may be attributable to the relatively nonreligious self-characterization of study participants, it has an important implication regarding spiritual care. Our participants reported that spiritual care was provided to individuals who were present to them in the context of recognized human value, dignity, and shared decision making, rather than through shared practices (ie, prayer), or through discussions of religious or theological issues at the bedside. . $^{8,36}$

To our knowledge, this study describes the first empirically based conceptual framework of spiritual caregiving. Sulmasy ${ }^{37}$ offers a model in which patients come to the clinical encounter in a spiritual and biopsychosocial state, which is a composite of the patient's spiritual history and their biopsychosocial makeup. Spiritual interventions may be introduced during this composite state by first modifying the spiritual state, which then affects the biopsychosocial state. ${ }^{37}$ Our data and conceptual framework suggest that spiritual care may be more integrated and process driven than the Sulmasy model.

Puchalski provides a role-based model of spiritual care in which an interdisciplinary care team member attends to a specific care dimension; however, the chaplain remains the primary spiritual caregiver. ${ }^{26}$ Another role-based model emphasizes a tiered approach to the spiritual assessment and care based on the individual competencies of the care team. ${ }^{38}$ In contrast to both models, our framework suggests that spiritual care may be effectively and interchangeably provided by multiple members of the care team.

As an exploratory study, our conceptual framework should be considered preliminary and open to modification. Qualitative studies are not statistically representative of any population, but they do provide an in-depth examination of complex phenomena, such as the investigation of spiritual care. ${ }^{24}$ The study was based on self-report of caregivers' perspectives, and we did not attempt to validate behaviors. Our nomination process presumed that participants saw themselves as providing spiritual care. It is possible that participants viewed the care that they described from a different framework, such as holistic care or the provision of emotional support. Even so, the interview guide included open-ended questions that asked participants how they understood and defined spiritual care.

In summary, we found that clinicians and other health caregivers who provide end-of-life spiritual care describe a series of highly fluid interpersonal processes-in the context of mutually recognized human values and experiences-rather than a set of prescribed and proscribed roles. Being present, open eyes, and cocreating are the primary components in a conceptual framework that depicts these processes. Future research directions may include a comparable study with patients and family caregivers at various stages of palliation to determine the degree of concordance across these stakeholders. Preliminary intervention work should focus on the applicability of this framework to enhance the spiritual care and, concomitantly, the overall care of patients living in the light of death.

To read or post commentaries in response to this article, see it online at http://www.annfammed.org/cgi/content/full/6/5/406.

Key words: Spirituality; end-of-life care; palliative care 
Submitted January 7, 2008; submitted, revised, April 16, 2008; accepted May 9, 2008.

Funding support: Supported by the Fetzer Institute and the UNC Center for Health and Aging

\section{References}

1. Numbers RL, Amundsen DW. Caring and Curing, Health and Medicine in Western Religious Traditions. Baltimore, MD: Johns Hopkins University Press; 1986.

2. Emanuel EJ, Emanuel LL. The promise of a good death. Lancet. 1998;351(suppl 2):S21-S29.

3. Teno JM, Clarridge BR, Casey V. etal. Family perspectives on endof-life care at the last place of care. JAMA. 2004;291(12):88-93.

4. Steinhauser KE, Christakis NA, Clipp EC, McNeilly M, McIntyre L, Tulsky JA. Factors considered important at the end of life by patients, family, physicians, and other care providers. JAMA. 2000;284(19):2476-2482

5. Walter T. Spirituality in palliative care: opportunity or burden? Palliat Med. 2002;16(2):133-139.

6. Yeung EW, French $P$, Leung AO. The impact of hospice inpatient care on the quality of life of patients terminally ill with cancer. Cancer Nurs. 1999;22(5):350-357.

7. Hermann CP. Spiritual needs of dying patients: a qualitative study. Oncology Nursing Forum. 2001;28(1):67-72.

8. Lo B, Ruston D, Kates LW, et al. Discussing religious and spiritual issues at the end of life. JAMA. 2002;287(19):749-754.

9. Fehring RJ, Miller JF, Shaw C. Spiritual well-being, religiosity, hope, depression, and other mood states in elderly people coping with cancer. Oncol Nurs Forum. 1997;24(4):663-671.

10. The Association of Professional Chaplains, The Association for Clinical Pastoral Education, The Canadian Association for Pastoral Practice and Education, The National Association of Catholic Chaplains, The National Association of Jewish Chaplains. A White Paper. Professional chaplaincy: its role and importance in healthcare. J Pastoral Care. 2001;55(1):81-97.

11. Sloan RP, Bagiella E, Powell T. Religion, spirituality, and medicine. Lancet. 1999;353(9153):664-667.

12. Lawrence RJ. The witches' brew of spirituality and medicine. Ann Behav Med. 2002;24(1):74-76.

13. Curlin FA, Lawrence RJ, Chin MH, Lantos JD. Religion, conscience, and controversial clinical practices. N Engl J Med. 2007;356(6):593-600.

14. Shea J. Spirituality and Health Care, Reaching Toward a Holistic Future Chicago, IL: The Park Ridge Center; 2000.

15. Ross L. Spiritual care in nursing: an overview of the research to date. J Clin Nurs. 2006;15(7):852-862.

16. Field MJ, Cassel CK. Approaching Death. Washington, DC: National Academy Press; 1997.

17. National Hospice and Palliative Care Organization. http://www. nhpco.org/i4a/pages/index.cfm?pageid $=3253$ \&openpage $=3253 \# \mathrm{~A}$ bout. Accessed May 31, 2005.
18. World Health Organization. WHO definition of palliative care World Health Organization. http://www.who.int/cancer/palliative/ definition/en/. Accessed Mar 19, 2007.

19. Millison MB. A review of the research on spiritual care and hospice. Hosp J. 1995;10(4):3-18.

20. Sinclair S, Pereira J, Raffin S. A thematic review of the spirituality literature within palliative care. J Palliat Med. 2006;9(2):464-479.

21. Hanson LC, Dobbs D, Usher B, Williams SW, Rawlings J, Daaleman TP. Providers and types of spiritual care experienced during serious illness. J Palliat Med. (accepted for publication).

22. Crabtree BF, Miller WL. Doing Qualitiative Research. 2nd ed. Thousand Oaks, CA: Sage; 1999.

23. QSR N6 [computer program]. Melbourne, Australia: QSR International Pty Ltd; 2002.

24. Miles MB, Huberman AM. Qualitative Data Analysis. Thousand Oaks, CA: Sage Publications; 1994

25. Speck P, Higginson I, Addington-Hall J. Spiritual needs in health care. BMJ. 2004;329(7458):123-124.

26. Puchalski CM, Lunsford B, Harris MH, Miller RT. Interdisciplinary spiritual care for seriously ill and dying patients: a collaborative model. Cancer J. 2006;12(5):398-416.

27. Taylor EJ, Highfield M, Amenta M. Attitudes and beliefs regarding spiritual care. A survey of cancer nurses. Cancer Nurs. 1994;17(6):479-487.

28. Wright MC. The essence of spiritual care: a phenomenological enquiry. Palliat Med. 2002;16(2):125-132.

29. Rumbold B, ed. Spirituality and Palliative Care. South Melbourne, Victoria: Oxford University Press; 2002.

30. Lunn JS. Spiritual care in a multi-religious context. J Pain Palliat Care Pharmacother. 2003;17(3-4):153-166.

31. Touhy TA, Brown C, Smith CJ. Spiritual caring, end of life in a nursing home. J Gerontol Nurs. 2005;31(9):27-35.

32. Pope John Paul II. Laborem Exercens. Washington, DC: United States Catholic Conference; 1981.

33. U.S. Catholic Bishops. Economic Justice for All: Pastoral Letter on Catholic Social Teaching and the U.S. Economy. Washington, D.C.: United States Catholic Conference; 1986.

34. Incandela JM. Playing God: divine activity, human activity, and Christian ethics. http://www.crosscurrents.org/Incandela.htm. Accessed Mar 16, 2006.

35. Chibnall JT, Bennett ML, Videen SD. etal. Identifying barriers to psychosocial spiritual care at the end of life: a physician group study. Am J Hosp Palliat Care. 2004;21(6):419-426.

36. Sulmasy DP. Spiritual issues in the care of dying patients. JAMA. 2006;296(11):1385-1392.

37. Sulmasy DP. A biopsychosocial-spiritual model for the care of patients at the end of life. Gerontologist. 2002;42(Spec No. 3):24-33.

38. Gordon T, Mitchell D. A competency model for the assessment and delivery of spiritual care. Palliat Med. 2004;18(7):646-651. 